\title{
Penentuan Bulk Density Ultisol Di Lahan Praktek Terbuka Universitas Labuhanbatu
}

\author{
Fitra Syawal Harahap ${ }^{1}$, Roswita Oesman², Wizni Fadhillah ${ }^{3}$, Ade Parlaungan Nasution ${ }^{4}$ \\ ${ }^{1}$ Program Studi Agroteknologi, Fakultas Sains dan Teknologi, Universitas Labuhanbatu \\ ${ }^{2}$ Program Studi Agroteknologi, Fakultas Pertanian, Universitas Pembinaan Masyarakat Indonesia \\ ${ }^{3}$ Program Studi Agroteknologi, Fakultas Pertanian, Universitas Muhammadiyah Sumatera Utara \\ ${ }^{4}$ Program Studi Manajemen, Fakultas Ekonomi dan Bisnis, Universitas Labuhanbatu
}

Email: fitrasyawalharahap@gmail.com

\begin{abstract}
Abstrak
Bulk density merupakan berat suatu massa tanah per satuan volume tertentu. Volume tanah adalah volume kepadatan tanah termasuk poripori tanah. Tanah yang lebih padat mempunyai bulk density yang lebih besar dari tanah yang sama tetapi kurang padat. pada umumnya tanah lapisan atas pada tanah mineral mempunyai nilai bulk density yang lebih rendah dibandingkan dengan tanah dibawahnya. Tujuan penelitian ini adalah Bulk density adalah untuk mengetahui berat jenis atau Bulk density pada lahan terbuka di lahan praktek dikarenakan sering dilakukan pengolahan tanah oleh mahasiswa Universitas Labuhanbatu Penelitian ini dilaksanakan di Lahan Praktek Universitas Labuhanbatu Rantauprapat, Kabupaten Labuhanbatu dengan ketinggian kurang lebih 18 meter diatas permukaan laut, Analisa tanah dilakukan di laboratorium ilmu terpadu fakultas sains dan teknologi Universitas Labuhanbatu. Penelitian ini dilaksanakan pada bulan Januari 2021 sampai April 2021. Hasil pengamatan yang diperoleh menunjukkan nilai bulk density untuk tanah yang diamati sebesar $1,060 \mathrm{gram} / \mathrm{cm}^{3} \mathrm{sehingga}$ Ketersediaan bahan organik juga berpengaruh hal ini disebabkan karena semakin banyak bahan organic yang terkandung dalam tanah maka semakin tinggi kepadatan tanah.
\end{abstract}

Kata Kunci : Bulk Density; Lahan Terbuka; Lapisan Atas; Volume Tanah

\section{Determination Of Ultisol Bulk Density In Open Land Of Universitas Labuhanbatu}

\begin{abstract}
Bulk density is the weight of a given soil mass per unit volume. Soil volume is the volume of soil density including soil pores. Soil that is denser has a bulk density that is greater than that of the same soil but is less dense. In general, the topsoil on mineral soils has a lower bulk density value than the subsoil. The purpose of this study is Bulk density is to determine the density or Bulk density on open land in practice land because soil processing is often carried out by Labuhanbatu University students. Soil analysis is carried out in the integrated science laboratory of the Faculty of Science and Technology, Labuanbatu University. This research was conducted from January 2021 to April 2021. The results obtained showed that the bulk density value for the observed soil was $1.060 \mathrm{gram} / \mathrm{cm}^{3}$ so that the availability of organic matter also had an effect, this was because the more organic matter contained in the soil, the higher the density soil.
\end{abstract}

Keywords: Bulk Density; Open Land; Top Layer; Soil Volume

\section{Pendahuluan}

Bulk density merupakan petunjuk kepadatan tanah. Makain padat suatu tanah makin tinggi bulk Density, yang berarti makin sulut meneruskan air atau ditembus akar tanaman Wawointana et al., (2020) Tanah yang lebih padat memilki bulk density yang lebih besar dari tanah yang sama tetapi kurang padat sehingga pada umumnya tanah lapisan atas pada tanah mineral mempunyai bulk density yang lebih rendah dibandingkan dengan tanah dibawahnya (Luta et al., 2020). Nilai bulk density tanah mineral berkisar 1-0,7 $\mathrm{gr} / \mathrm{cm} 3$, sedangkan tanah organic umumnya memiliki BD antara 0,1-0,9 $\mathrm{gram} / \mathrm{cm}^{3}$ (Hakansson and Lipiec, 200).

Bulk density (berat isi) adalah perbandingan berat tanah kering dengan satuan volume tanah termasuk volume pori-pori tanah, umumnya dinyatakan dalam $\mathrm{gr} / \mathrm{cm}^{3}$. Sedangkan bentuk density adalah berat suatu massa tanah persatuan volume tanpa pori-pori tanah dengan $\mathrm{gr} / \mathrm{cm}^{3}$ (Hanif et al., 2020). Sampel tanah yang diambil untuk menentukan berat jenis pasir halus diambil dengan hati-hati dari dalam tanah. Bulk density ditentukan dengan mengukur massa tanah di udara dan massa air demikian pula halnya dengan berat per satuan volumenya. (Arsyad, A.R., 2004).

Tanah yang lepas dan berkumpul akan mempunyai berat persatuan volume yang mudah dan tanah yang lebih tinggi kerapatan massanya. Butiran-butiran pasir letaknya cenderung untuk erat satu sama lainnya (Harahap et al., 2020). Kandungan bahan-bahan organik rendah dari tanah berpasir dan mempertinggi kerapatan massa, sebaliknya butir-butir tanah yang permukaannya halus, mempunyai letak yang tidak begitu erat satu sama lainnya. Hal ini akibat kenyataan bahwa permukaan tanah relatif berbutirbutir (Indrawahyuni, dan Damayanti, 2012).

Kerapatan massa adalah bobot massa tanah kondisi lapangan yang dikering ovenkan persatuan volume. Nilai kerapatan massa tanah berbanding lurus dengan tingkat 
kekasaran partikel-partikel tanah, makin kasar akan makin berat (Jepsen et al., 1997). Tanah lapisan atas yang bertekstur liat dan berstruktur granular memiliki BI anatara $1,0-1.3 \mathrm{~g} / \mathrm{cm}^{-3}$, sedangkan yang bertekstur kasar memiliki BI 1,3 - 1,8 g/ $\mathrm{cm}^{-3}$ (Hanafiah, 2005).

Bila dinyatakan dalam gram $/ \mathrm{cm}^{3}$, kerapatan massa tanah liat yang ada di permukaan dengan struktur granular besarnya berkisar antara 1,0 sampai 1,3 dengan tanahtanah permukaan dengan tekstur kasar mempunyai kisaran 1,3 sampai 1,8 (Keller et al., 2010). Perkembangan struktur yang lebih besar pada tanah-tanah di permukaan dengan tekstur halus, menyebabkan kerapatan massanya lebih rendah dibandingkan dengan tanah berpasir (Foth, 1994).

Bulk Density dipengaruhi oleh faktor-faktor tekstur, struktur dan kandungan bahan organik sehingga bulk density dengan cepatnya berubah karena pengolahan tanah dan praktek budidaya (Logsdon dan Karlen, 2004). Hubungannya dengan tekstur adalah liat memiliki pori yang kecil karena tingkat kepadatannya tinggi sehingga berpengaruh terhadap $\mathrm{BD}$ nya, sama juga halnya dengan struktur tanah (Lee et al., 2009).

Ketersediaan bahan organik juga berpengaruh hal ini disebabkan karena semakin banyak bahan organik yang terkandung dalam tanah maka semakin tinggi BD nya. (Harahap et al., 2018). Ultisol mempunyai permeabilitas lambat hingga sedang dan tingkat kepadatan atau BD di atas $1,3 \mathrm{~g} / \mathrm{cm}^{3}$ yang mengakibatkan penetrasi akar tanaman tidak dapat berkembang dengan baik (Sequeira et al., 2014).

Ultisol adalah tanah dengan horizon argilik bersifat masam dengan kejenuhan basa lebih kecil dari $35 \%$ pada kedalaman 1,8 $\mathrm{m}$ dari permukaan tanah. Tanah ini berkembang dari bahan induk tua, di Indonesia banyak ditemukan pada daerah-daerah dengan bahan induk batuan liat (Hanif et al., 2020).Sehingga Tujuan penelitian ini adalah Bulk density adalah untuk mengetahui berat jenis atau Bulk density pada lahan terbuka di lahan praktek Universitas Labuhanbatu.

\section{Metodologi}

Penelitian ini dilaksanakan di Lahan Praktek Universitas Labuhanbatu Rantauprapat, Kabupaten Labuhanbatu dengan ketinggian kurang lebih 18 meter diatas permukaan laut, Analisa tanah dilakukan di laboratorium ilmu terpadu Fakultas Sains dan Teknologi Universitas Labuhanbatu. Penelitian ini dilaksanakan pada bulan Januari 2021 sampai April 2021.
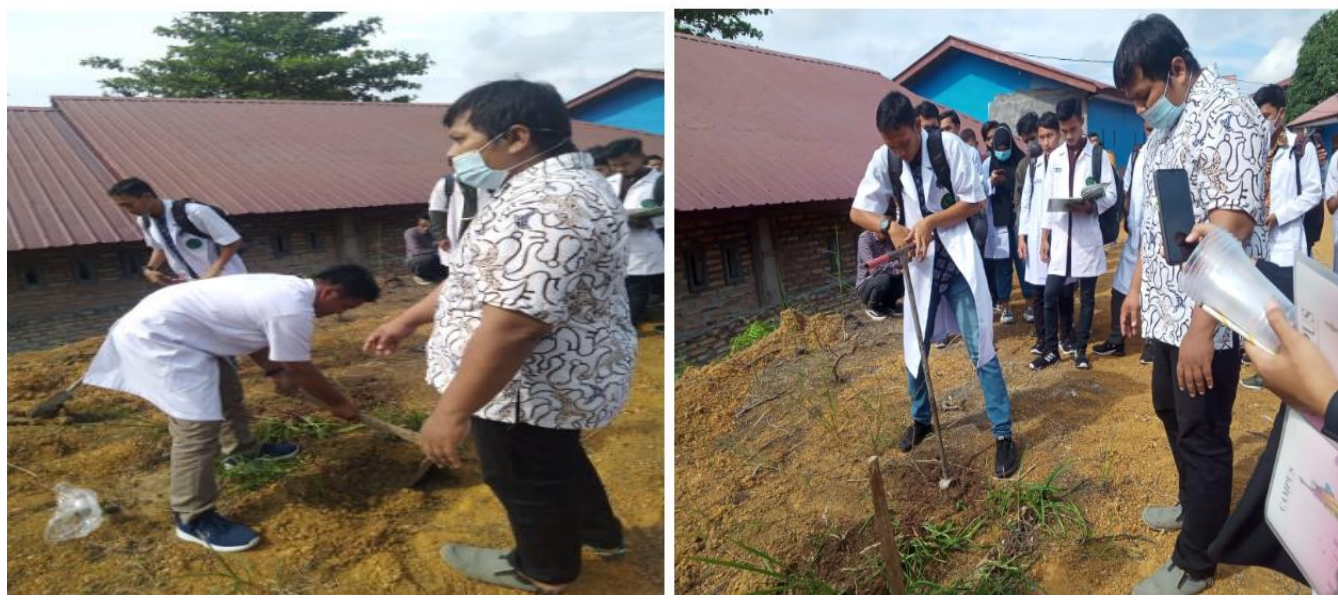

Gambar 1. Lokasi Pengambilan Sampel Tanah

Penelitian dimulai dengan pengambilan sampel tanah. Metode yang digunakan dalam penelitian ini adalah metode survey grid bebas tingkat survei semi detail (kerapatan pengamatan 1 sampel tiap 100 meter) Pelaksanaan pengambilan contoh tanah sebanyak 5 titik sampel dengan jarak 100 meter dilapangan yang menggunakan metode acak tersebar dengan luasan yang telah ditentukan dengan berpedoman pada peta dasar dengan cara sebagaimana disajikan pada Gambar 2. Pengambilan contoh tanah menggunakan cangkul/ bor tanah pada kedalaman $0-20 \mathrm{~cm}$ dan dilakukan pencatatan hasil pembacaan koordinat pada GPS (Rauf dan Harahap, 2019).

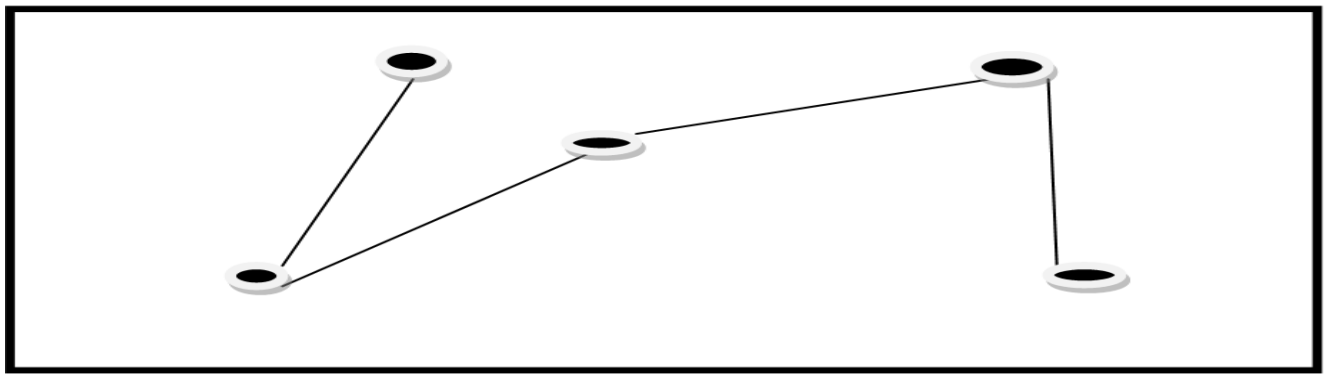

Gambar 2. Titik samping pengambilan sampel tanah di lokasi penelitian 
Adapun Parameter yang diamati meliputi pengamatan Bulk Density yaitu dengan menggunakan sample tanah dari pengamatan profil yaitu sample tanah utuh yang diambil dengan ring sampel, kemudian sample tanah tersebut dimasukkan ke dalam oven 2 hari sebelum pengambilan sampel tanah dilahan. Setelah diovenkan, sample tanah tersebut dimasukkan ke dalam desikator untuk didinginkan, kemudian timbang tanah beserta ring sampelnya. Selanjutnya keluarkan sample tanahnya lalu timbang ring sampelnya. Dengan Menghitung Bulk density dengan persamaan :

Keterangan :

$$
B D=\frac{\text { Berat Tanah Kering }}{\text { Volume Tanah }} \mathrm{gr} / \mathrm{cm}^{3}
$$

$\begin{aligned} \text { Volume tanah } & =\pi \mathrm{r}^{2} \mathrm{t} \\ \mathrm{T} & =\operatorname{tinggi} \operatorname{ring} \operatorname{sampel}(\mathrm{cm}) \\ \mathrm{r} & =\text { jari-jari }(\mathrm{cm}) \\ \pi & =3,14\end{aligned}$

\section{Hasil}

Hasli penelitian yang telah dilakukan pada pengambilan sampel bulk density maka diperoleh bulk

density ultisol di lahan praktek terbuka Universitas Labuhanbatu disajikan Pada Tabel 1, Sebagai berikut:

Tabel 1. Pengamatan Bulk Density

\begin{tabular}{cc}
\hline Lokasi & Nilai Bulk Density $\left(\mathbf{g r} / \mathbf{c m}^{\mathbf{3}}\right)$ \\
\hline L0 & 1,101 \\
L1 & 1,060 \\
L2 & 1,024 \\
L3 & 1,071 \\
L4 & 1,051 \\
L5 & 1,054 \\
Rata-Rata & $\mathbf{1 , 0 6 0}$ \\
\hline
\end{tabular}

Sumber : Data Primer 2014

Hasil pengamatan pada Tabel 1. dapat dilihat bahwa pada tanah ultisol di lahan praktek terbuka Universitas Labuhanbatu memiliki nilai bulk density adalah 1,101 $\mathrm{gr} / \mathrm{cm}^{3}$ sampai dengan $1,071 \mathrm{gr} / \mathrm{cm}^{3}$ sehingga dapat dikatakan bahwa kepadatan bulk densitynya rendah, hal terjadi ini dikarenakan pada lapisan pertama bulk densitynya dipengaruhi oleh tinggi rendahnya bahan organik. Sedikitnya kandungan bahan organik pada tanah ultisol dilahan praktek Universitas Labuhanbatu disebabkan karena lapisan ini terletak dekat dengan batuan induk, sehingga lebih banyak mengandung pasir. pasir memiliki kandungan bahan organik yang sedikit. hal ini sesuai dengan pendapat Hardjowigeno (2003) yang menyatakan bahwa tanah yang berstruktur halus mempunyai porositas tinggi dan berat isi yang lebih rendah daripada tanah berpasir.

Tanah yang mengandung bahan organik yang tinggi akan memiliki nilai Bulk density yang rendah, sebaliknya tanah yang mengandung bahan organik yang rendah memiliki nilai Bulk density yang tinggi. Hal ini juga sesuai dengan pendapat Hanafiah (2005) bahwa kandungan bahan organik yang cukup mempengaruhi nilai butiran tanah karena bahan organik yang sangat ringan sehingga mempengaruhi kepadatan tanah. .

Adapun faktor-faktor yang mempengaruhi Bulk Density adalah tekstur, struktur, dan kandungan bahan organik serta pengelolahan tanah dan praktek budidaya. Kandungan bahan organik dikatakan berpengaruh karena pada umumnya tanah lapisan atas mempunyai nilai Bulk Density yang lebih rendah dibandingkan dengan tanah yang berada di bawahnya ini terjadi karena adanya pengaruh bahan organik (Darmayanti, A.S., 2012). Hal ini sesuai dengan pendapat Susanti et al., (2019) bahwa bahan organik yang terdapat pada tanah mempunyai pengaruh yang besar yaitu bahan organik dapat memperkecil nilai Bulk Density karena bahan organik jauh lebih ringan daripada mineral.

\section{Kesimpulan}

Tanah pada tanah Ultisol dilahan Praktek Universitas Labuhanbatu memiliki nilai Bulk density $1,060 \mathrm{gr} / \mathrm{cm}^{3}$ sehingga faktor-faktor yang mempengaruhi partikel density adalah bulk density secara tidak langsung berhubungan dengan kandungan bahan organik, tekstur dan struktur tanah.

\section{Daftar pustaka}

Arsyad, A.R., 2004. Pengaruh Olah Tanah Konservasi Dan Pola Tanam Terhadap Sifat Fisika Tanah Ultisol Dan Hasil Jagung [The Effect Of Conservation Tillage And Cropping System On Physical Soil Properties And Maize Yield]. Jurnal Agronomi, 8(2), pp.111-116.

Buckman, 1982. Ilmu Tanah. Bhatara Karya Angkasa, Jakarta.

Darmayanti, A.S., 2012. Beberapa sifat fisika kimia tanah yang berpengaruh terhadap model kecepatan infiltrasi pada tegakan mahoni, jabon, dan trembesi di Kebun Raya Purwodadi. Berkala Penelitian Hayati, 17(2), pp.185-191.

Foth, 1989. Dasar-Dasar llmu Tanah. Gadjah Mada University Press, Yogyakarta.

Hakansson, I. and Lipiec, J., 2000. A review of the usefulness of relative bulk density values in studies of soil structure and compaction. Soil and Tillage Research, 53(2), pp.71-85. 
Hanafiah, A. 2005. Dasar-dasar Ilmu Tanah. PT. Raja Grafindo Persada. Jakarta.

Hanif, A., Harahap, F.S., Novita, A., Rauf, A., Oesman, R. And Hernosa, S.P., 2020, February. Conservation Soil Processing Test on The Improvement of Soil Physics Properties. In Proceeding International Conference Sustainable Agriculture and Natural Resources Management (ICoSAaNRM) (Vol. 2, No. 01).

Harahap, F.S., Rauf, A., Susanti, R., Afriani, A. and Fuad, C., 2018. Pengujian Pengolahan Tanah Konservasi Dengan Pemberian Mikoriza Serta Varietas Kacang Tanah Terhadap Sifat Kimia Tanah. In Prosiding Seminar Nasional Pertanian (Vol. 1, No. 1).

Hardjowigeno, S. 2003. Klasifikasi Tanah dan Pedogenesis. Akadeika Presindo. Jakarta

Indrawahyuni, H. and Damayanti, I., 2012. Pengaruh variasi kepadatan pada permodelan fisik menggunakan tanah pasir berlempung terhadap stabilitas lereng. Rekayasa Sipil, 3(3), pp.192-208.

Jepsen, R., Roberts, J. and Lick, W., 1997. Effects of bulk density on sediment erosion rates. Water, Air, and Soil Pollution, 99(1), pp.21-31.

Keller, T. and Håkansson, I., 2010. Estimation of reference bulk density from soil particle size distribution and soil organic matter content. Geoderma, 154(3-4), pp.398-406

Lee, J., Hopmans, J.W., Rolston, D.E., Baer, S.G. and Six, J., 2009. Determining soil carbon stock changes: simple bulk density corrections fail. Agriculture, Ecosystems \& Environment, 134(34), pp.251-256.

Logsdon, S.D. and Karlen, D.L., 2004. Bulk density as a soil quality indicator during conversion to no-tillage. Soil and Tillage Research, 78(2), pp.143-149.

Luta, D.A., Siregar, M., Sabrina, T. and Harahap, F.S., 2020. Peran aplikasi pembenah tanah terhadap sifat kimia tanah pada tanaman bawang merah. Jurnal Tanah dan Sumberdaya Lahan, 7(1), pp.121-125.

Prasetiyo, A., Djajadi, D. and Sudarto, S., 2017. Kajian Produktivitas Dan Mutu Tembakau Temanggung Berdasarkan Nilai Indeks Erodibilitas Dan Kepadatan Tanah. Jurnal Tanah dan Sumberdaya Lahan, 3(2), pp.389-399.

Rauf, A. and Harahap, F.S., 2019. Optimalisasi Lahan Pertanian Menggunakan Agen Biomassa.

Sakin, E., 2012. Organic carbon organic matter and bulk density relationships in arid-semi arid soils in Southeast Anatolia region. African Journal of Biotechnology, 11(6), pp.1373-1377.

Sequeira, C.H., Wills, S.A., Seybold, C.A. and West, L.T., 2014. Predicting soil bulk density for incomplete databases. Geoderma, 213, pp.64-73.

Susanti, R., Afriani, A. and Harahap, F.S., 2019. 34 Aplikasi Mikoriza dan Beberapa Varietas Kacang Tanah Dengan Pengolahan Tanah Konservasi terhadap Perubahan sifat Biologi Tanah. Jurnal Pertanian Tropik, 6(1), pp.34-42.

Wawointana, A.C., Pongoh, J. and Tilaar, W., 2018. PENGARUH Varietas Dan Jenis Pengolahan Tanah Terhadap Pertumbuhan Dan Hasil Tanaman Jagung (Zea mayz, L.). JURNAL Lppm Bidang Sains Dan Teknologi, 4(2), pp.79-83. 